\title{
A Comparison of Performance of Landfill Gas Collection Wells with Varying Configurations
}

\author{
Chien-Kai Wang and Gopal Achari*
}

Department of Civil Engineering, Schulich School of Engineering, University of Calgary, Calgary, Alberta, Canada

\begin{abstract}
An investigation to compare the efficiency of landfill gas collection systems with different well numbers (one, two or four) and configurations (vertical or horizontal) has been conducted. The study has shown that with an increasing number of wells, the gas collection rate and efficiency are enhanced and the gas flux at the surface also becomes more uniform. In addition, the study has also suggested that for wells with the same screen length, a vertical well works better than a horizontal well in terms of gas extraction rate; however, it may result in a less uniform gas flux through the surface.
\end{abstract}

Keywords: Landfill gas, gas extraction wells, LFG recovery, surface emission, air intrusion.

\section{INTRODUCTION}

The decomposition process of organic matter buried in landfills can be categorized into two phases: the aerobic phase and the anaerobic phase. As soon as waste is buried in a landfill, it starts to degrade aerobically consuming the oxygen in the pores, once the oxygen is depleted, the anaerobic phase begins. During the anaerobic degradation stage, landfill gas, which primarily consists of methane $\left(\mathrm{CH}_{4}\right)$ and carbon dioxide $\left(\mathrm{CO}_{2}\right)$ with minor amount of other constituents, is produced [1-4]. Although gas generation and composition may differ amongst landfills, due to differences in temperature, moisture content, $\mathrm{pH}$, waste composition and other factors [5], methane generally accounts for around 50$55 \%$ of the overall landfill gas generation with most of the remaining $45-50 \%$ being carbon dioxide $[4,6,7]$. Methane, a greenhouse gas that stays in the atmosphere for approximately 12 years, is around 20 to 25 times more effective than carbon dioxide in retaining heat in the atmosphere over a 100 -year period. Methane is also the most important anthropogenic contributor to the global climate change after carbon dioxide [3, 5, 8-11].

Equipping a landfill with a gas collection system becomes a possible solution for reducing methane emissions while providing a source of clean energy and diminishing the risk of any unwanted explosion. However, installing a gas collection system in a landfill is not always economically feasible and a bad setting of the gas collection wells may prohibit the system from reaching its maximum potential. In order to achieve the highest possible efficiency of a gas collection system, a simulation on its performance with various configurations prior to the installation will be beneficial.

With intent to maximize gas extraction while minimizing surface emission and air intrusion, this paper presents a comparison of performance among gas extraction systems

*Address correspondence to this author at the Department of Civil Engineering, Schulich School of Engineering, University of Calgary, Calgary, Alberta, Canada; Tel: 403-220-6599; Fax: 403-282-7026;

E-mail: gachari@ucalgary.ca with various configurations using a three-dimensional model that is previously developed. The model has been used to study how the number of wells and the directions they are placed in a landfill may influence the gas collection efficiency and the magnitude of surface emission and air intrusion.

\section{METHODOLOGY}

In this paper, landfill gas is assumed to consist of an equal amount of methane and carbon dioxide; temperature within the landfill is assumed to be $310 \mathrm{~K}$. In addition, since the advective transport is the overriding mechanism that is usually found to be more than three orders of magnitude larger than the diffusive transport in a landfill [12], diffusion is neglected in this model.

\section{MATHEMATIC FORMULATION}

The governing equation used to describe the landfill gas movement is written as:

$$
\phi \cdot S \frac{\partial P}{\partial t}+\nabla \cdot\left[\frac{k_{i}}{\eta}(\nabla p+\rho g)\right]=Q
$$

where $\phi$ is the porosity of the landfill $\left[\mathrm{m}^{3} \mathrm{~m}^{-3}\right]$; $\mathrm{S}$ is the gas compressibility $\left[\mathrm{Pa}^{-1}\right] ; \mathrm{P}$ is the landfill gas pressure $[\mathrm{Pa}] ; \mathrm{k}_{\mathrm{i}}$ is the permeability $\left[\mathrm{m}^{2}\right] ; \eta$ is the landfill gas viscosity $[\mathrm{Pa} \mathrm{s}]$; $\rho$ is the gas density $\left[\mathrm{kg} \mathrm{m}^{-3}\right]$; $\mathrm{g}$ is the acceleration due to gravity $\left[\mathrm{m} \mathrm{s}^{-2}\right]$; and $\mathrm{Q}$ is the volume of gas generated per unit volume of space per unit of time $\left[\mathrm{m}^{3} \mathrm{~m}^{-3} \mathrm{~s}^{-1}\right]$.

As the gas pressure in a landfill hardly goes up by more than $3 \sim 4 \mathrm{kPa}$ above the atmospheric pressure, the ideal gas law is assumed to hold true in the model. The ideal gas law can be written as:

$V=\frac{n R T}{P}$

where $\mathrm{V}$ is the volume of gas $\left[\mathrm{m}^{3}\right] ; \mathrm{n}$ is the number of gas molecules [mol]; $\mathrm{R}$ is the universal gas constant $\left[\mathrm{kg} \mathrm{m}^{2} \mathrm{~s}^{-2}\right.$ $\left.\mathrm{mol}^{-1} \mathrm{~K}^{-1}\right]$; and $\mathrm{T}$ is the gas temperature $[\mathrm{K}]$. 
The gas compressibility, sometimes referred to as coefficient of isothermal compressibility of gas, is defined as the fractional change of gas volume as pressure changes at constant temperature. The defining equation is [13]:

$$
S=-\frac{1}{V}\left(\frac{\partial V}{\partial P}\right)_{T}
$$

In order to eliminate the term $(\partial \mathrm{V} / \partial \mathrm{P})_{\mathrm{T}}$ in Eq. (3), a new equation is derived from Eq. (2) as [13]:

$\left(\frac{\partial V}{\partial P}\right)_{T}=-\frac{n R T}{P^{2}}$

Combining Eq. (3) and (4) gives [13]:

$S=\left(-\frac{1}{V}\right)\left(-\frac{n R T}{P^{2}}\right)$

Substituting $V$ in Eq. (5) with Eq. (2) and Eq. (6) is derived and illustrates that the gas compressibility is the inverse of pressure.

$S=\left(-\frac{P}{n R T}\right)\left(-\frac{n R T}{P^{2}}\right)=\frac{1}{P}$

$\mathrm{Q}$, the generation term $\left[\mathrm{m}^{3} \mathrm{~m}^{-3} \mathrm{~s}^{-1}\right]$, Eq. (1) can be rewritten as:

$Q=G_{v} * \rho_{b}$

where $\rho_{b}$ is the bulk density of the refuse $\left[\mathrm{kg} \mathrm{m}^{-3}\right]$; and $\mathrm{G}_{\mathrm{v}}$ is the volume of landfill gas that can be generated per unit mass of waste per second $\left[\mathrm{m}^{3} \mathrm{~kg}^{-1} \mathrm{~s}^{-1}\right]$, and $\mathrm{G}_{\mathrm{v}}$ can be represented by first order reaction kinetics given below:

$G_{v}=L_{0} \sum_{m=1}^{n} A_{m} k_{m} e^{-k_{m} t_{r}}$

where $\mathrm{L}_{0}$ is the ultimate landfill gas generation potential of the waste $\left[\mathrm{m}^{3} \mathrm{~kg}^{-1}\right] ; \mathrm{k}_{\mathrm{m}}$ is the first order reaction rate constant for component $\mathrm{m}$ of waste $\left[\mathrm{s}^{-1}\right] ; \mathrm{A}_{\mathrm{m}}$ is the fraction of component $\mathrm{m}$ in waste mass; and $\mathrm{t}_{\mathrm{r}}$ in the equation is the age of waste which can be expressed as the following equation assuming the landfill is filled at a constant rate.

$t_{r}=t_{0}+t_{f}\left(\frac{Z}{D}\right)$

where $t_{0}$ is the time since closure of the landfill $[\mathrm{s}], \mathrm{t}_{\mathrm{f}}$ is the total time to fill the landfill [s], $\mathrm{Z}$ is the depth of waste mass $[\mathrm{m}]$; and $\mathrm{D}$ is the total depth of the landfill [m].

\section{INITIAL AND BOUNDARY CONDITIONS}

The model comprises 3 types of sub-domains: waste, final cover, and the pseudo gas extraction well. Each domain has its own distinct properties and characteristics. The void space inside the extraction well is treated as a highly permeable porous medium with a porosity value of 1 . The majority of data used in the simulations were acquired from Chen et al. [14] and are listed in Table 1.

The sides and the bottom of the landfill are regarded as no flux boundaries since a landfill should be bounded by impermeable liners to prevent any leachate leakage to the surrounding areas. The wells are hollow pipes which are

Table 1. Input Data for the Model

\begin{tabular}{|c|c|c|c|}
\hline Parameters & Values & Parameters & Values \\
\hline Waste Domain & & Radius of the well (m) & 0.05 \\
\hline Bulk density $\left(\mathrm{kg} \mathrm{m}^{-3}\right)$ & 880 & Length of the vertical well (m) & 36 \\
\hline Porosity & 0.5 & Length of the horizontal well (m) & 60 \\
\hline Horizontal permeability $\left(\mathrm{m}^{2}\right)$ & $3 e-12$ & Length of the well screen (m) & \\
\hline Vertical permeability $\left(\mathrm{m}^{2}\right)$ & $1 e-12$ & Active gas collection system & 20 \\
\hline Final cover Domain & & Passive gas collection system & 35 \\
\hline Bulk density $\left(\mathrm{kg} \mathrm{m}^{-3}\right)$ & 1650 & Final cover thickness $(\mathrm{m})$ & 1 \\
\hline Porosity & 0.44 & Depth of refuse $(\mathrm{m})$ & 45 \\
\hline Horizontal permeability $\left(\mathrm{m}^{2}\right)$ & $1 \mathrm{e}-13$ & Width of the landfill (m) & 100 \\
\hline Vertical permeability $\left(\mathrm{m}^{2}\right)$ & $1 e-13$ & Length of the landfill (m) & 100 \\
\hline Pseudo Domain of Gas Extraction Wells & & Time to fill the landfill (yr) & 37 \\
\hline Bulk density $\left(\mathrm{kg} \mathrm{m}^{-3}\right)$ & 0 & Time since closure of the landfill (yr) & 0 \\
\hline Porosity & 1 & Temperature $(\mathrm{K})$ & 310 \\
\hline Horizontal permeability $\left(\mathrm{m}^{2}\right)$ & $3 e-3$ & Landfill gas viscosity ( $\mathrm{Pa} \mathrm{s}$ ) & $1.54 \mathrm{e}-5$ \\
\hline Vertical permeability $\left(\mathrm{m}^{2}\right)$ & $3 e-3$ & Landfill gas generation potential $\left(\mathrm{m}^{3} \mathrm{~kg}^{-1}\right)$ & 0.356 \\
\hline Refuse composition & & Refuse reaction rate constant & \\
\hline Readily biodegradable (\%) & 15 & Readily biodegradable $\left(\mathrm{yr}^{-1}\right)$ & 0.1386 \\
\hline Moderately biodegradable (\%) & 55 & Moderately biodegradable $\left(\mathrm{yr}^{-1}\right)$ & 0.0231 \\
\hline Slowly biodegradable (\%) & 30 & Slowly biodegradable $\left(\mathrm{yr}^{-1}\right)$ & 0.017328 \\
\hline
\end{tabular}


only permeable at the screen sections. In an active gas collection system, the screen length is $20 \mathrm{~m}$; while in a passive gas collection system, the screen section extends to the full length of the wells as the pipes are perforated all the way through. The pressure at the top of the well screen is set to be equal to the atmospheric pressure $(100.0 \mathrm{kPa})$ when the gas collection system is passive. When the gas collection system is active, the pressure applied in the wells is indicated in each individual simulation. Pressure at the surface of the final cover is set to be equal to the atmospheric pressure. The initial pressure within the waste and the final cover is also assumed to be the same as the atmospheric pressure. The atmospheric pressure in this model is arbitrarily fixed at $100.0 \mathrm{kPa}$. The configurations and boundary conditions of the model are illustrated in Fig. $(\mathbf{1} \mathbf{a}, \mathbf{b})$.

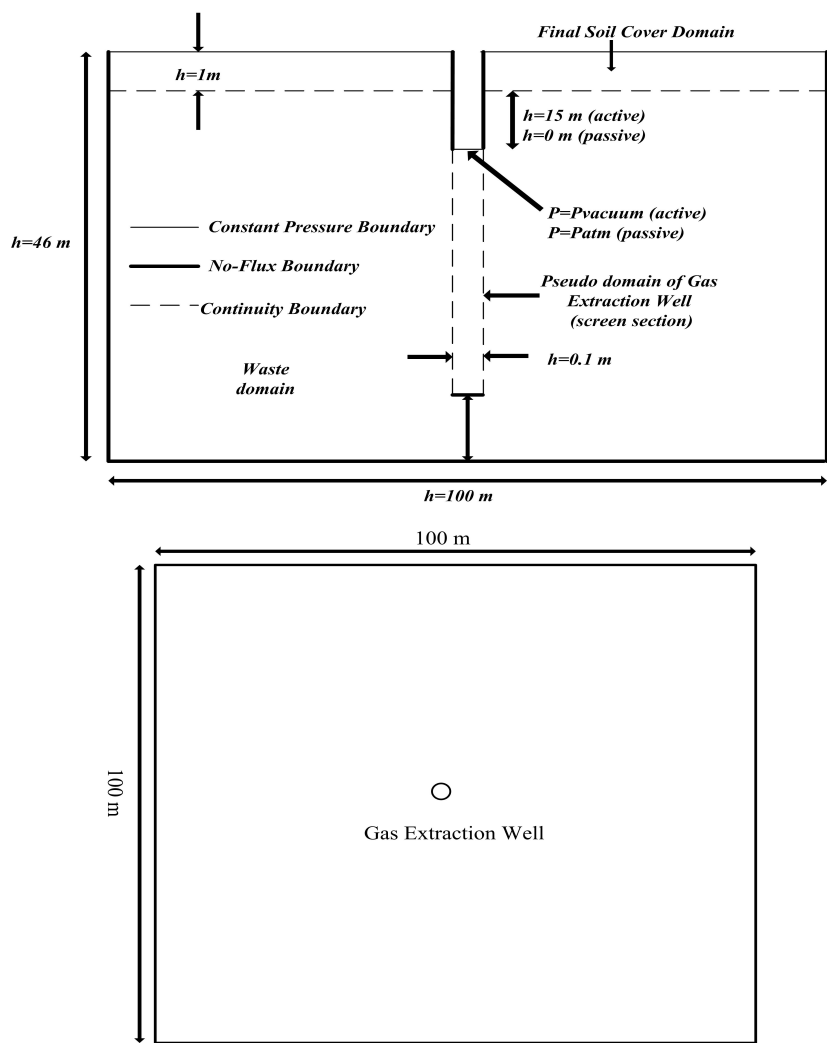

Fig. (1). (a) Profile of the landfill configuration and boundary conditions; (b). Plan view of the landfill configuration.

\section{RESULTS AND DISCUSSIONS}

In this study, simulations have been conducted to investigate the efficiency of a passive and an active gas collection system with one, two or four vertical wells installed in a landfill; in addition, a comparison of the efficiency of a vertical well and a horizontal well has been conducted.

\section{Effects of Varying the Number of Wells of a Passive Gas Collection System}

Investigations were done to study the efficiency of a passive gas collection system with one, two and four vertical gas extraction wells installed in a hypothetical landfill. The wells' physical settings are illustrated in Fig. (2a-c). Figs. (3, $\mathbf{4 a}, \mathbf{b})$ show the gas generation rate, gas collection rate, and overall surface emission rate from all three settings.
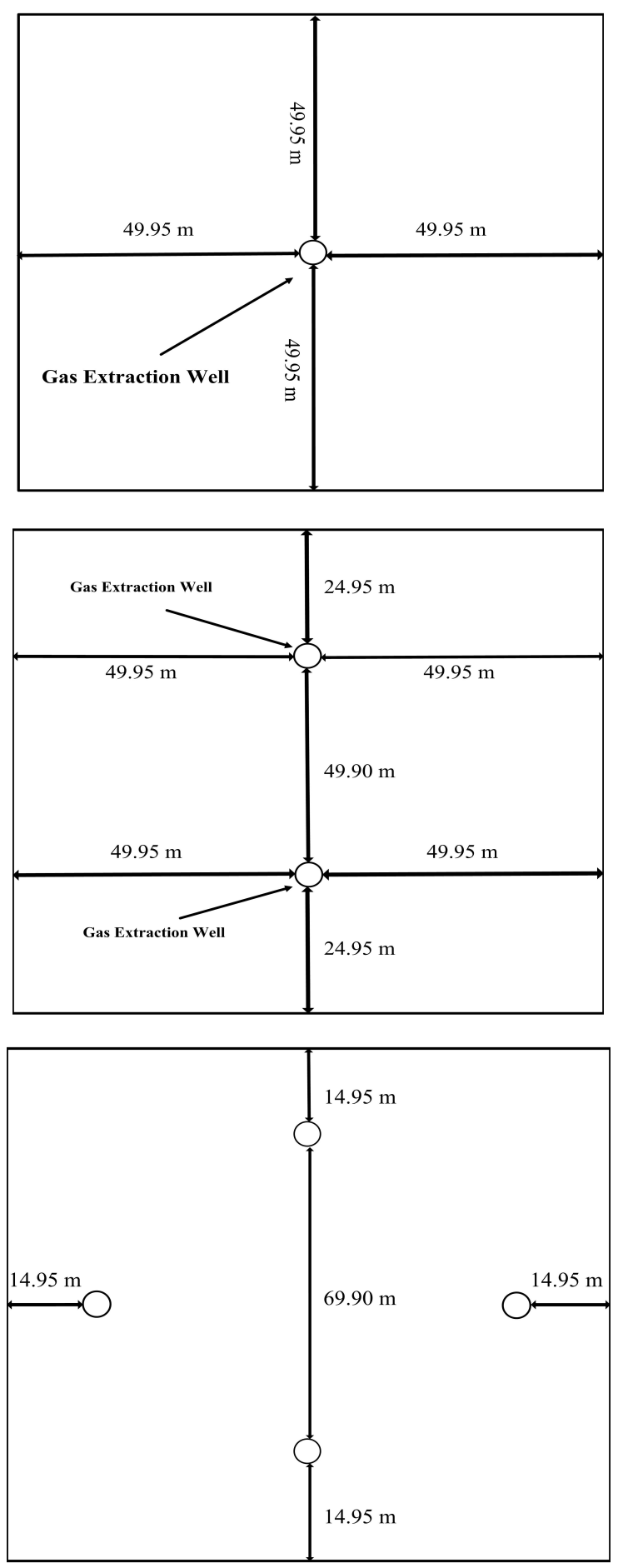

Fig. (2). Location of the well when the landfill is equipped with (a) one well; (b) two wells; (c) four wells.

Fig. (3) shows that the gas generation rate, following a first-order reaction kinetics, starts at $283 \mathrm{~m}^{3} \mathrm{hr}^{-1}$ and gradually decreases to $187 \mathrm{~m}^{3} \mathrm{hr}^{-1}$ ten years after the commence of the anaerobic phase. The gradual decrease in gas generation rate also results in a gradual decrease in gas collection rate and surface emission rate as demonstrated in Fig. (4a, b).

Fig. (4a, b) also illustrate that a larger number of wells can help to enhance the gas collection efficiency. When there 


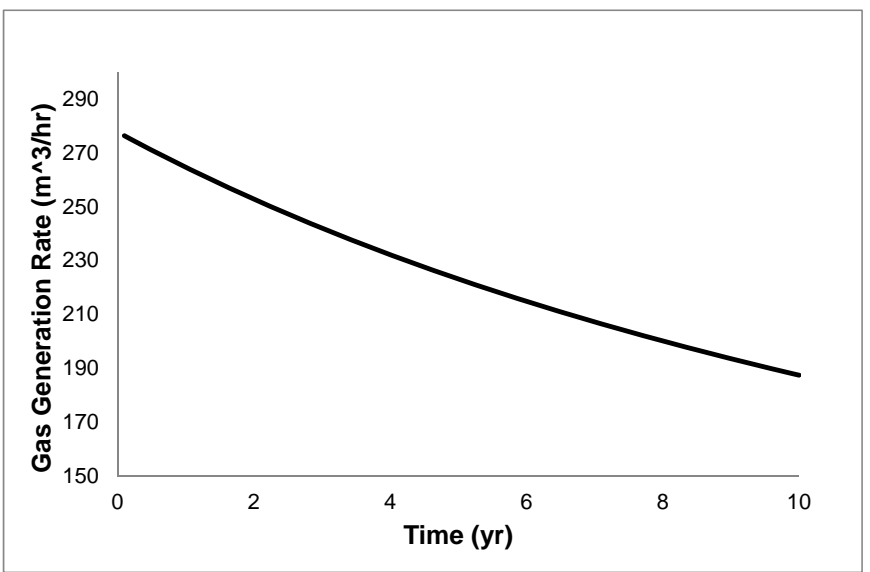

Fig. (3). Gas generation rate in the landfill for the first 10 years.
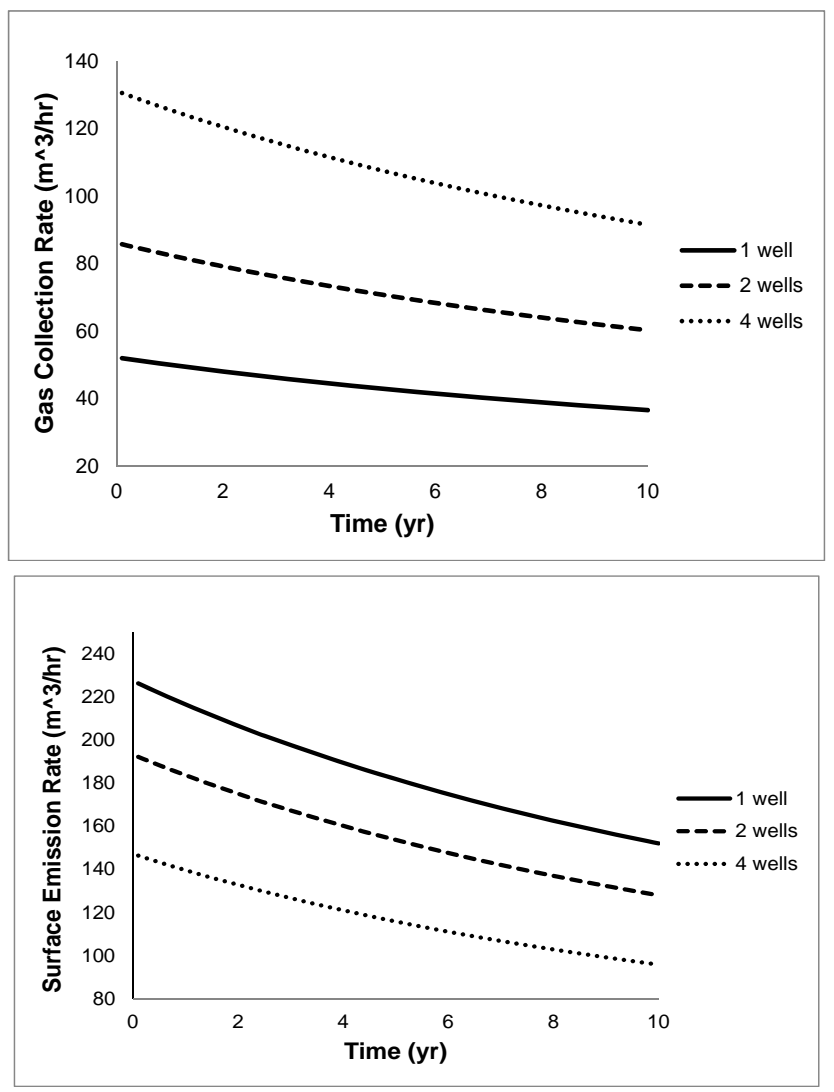

Fig. (4). (a) Overall gas collection rate from the passive gas collection systems with indicated number of wells; (b) Overall surface emission rate.

is only one well installed in the landfill, the gas collection rate starts from $52 \mathrm{~m}^{3} \mathrm{hr}^{-1}$ and then slowly diminishes to 43 $\mathrm{m}^{3} \mathrm{hr}^{-1}$ after five years and $37 \mathrm{~m}^{3} \mathrm{hr}^{-1}$ after ten years; following a similar trend, the overall surface emission rate starts from $226 \mathrm{~m}^{3} \mathrm{hr}^{-1}$ and then slowly decreases to $152 \mathrm{~m}^{3}$ $\mathrm{hr}^{-1}$ at year 10. The gas collection efficiency, which is calculated by dividing the amount of gas collected by the amount of gas generated each year, is around $19 \%$ within the first ten years. If an additional well is added, the gas collection efficiency rises to about $31 \%$ or a $64 \%$ increase as the gas collection rate goes up to $86 \mathrm{~m}^{3} \mathrm{hr}^{-1}$ at the beginning to $60 \mathrm{~m}^{3} \mathrm{hr}^{-1}$ at year 10 , while the overall surface emission rate goes down from $192 \mathrm{~m}^{3} \mathrm{hr}^{-1}$ to $128 \mathrm{~m}^{3} \mathrm{hr}^{-1}$ throughout the ten-year period. If the number of wells is further increased to four, the gas collection rate can be lifted to 131 $\mathrm{m}^{3} \mathrm{hr}^{-1}$ at the beginning and $92 \mathrm{~m}^{3} \mathrm{hr}^{-1}$ at year 10 . The overall surface emission rate, on the other hand, can be lowered to $146 \mathrm{~m}^{3} \mathrm{hr}^{-1}$ and $96 \mathrm{~m}^{3} \mathrm{hr}^{-1}$, and consequently, the gas collection efficiency is enhanced to $48 \%$ or a $149 \%$ increase compared to the one-well system. The gas collection efficiency figures suggest that with a passive gas collection system, increasing the number of wells can considerably increase the gas collection efficiency.

\section{Effects of Varying the Number of Wells of an Active Gas Collection System}

Simulations were also carried out to study the gas collection efficiency of an active gas collection system with one, two, and four vertical gas extractions wells. The wells all have a $20 \mathrm{~m}$ screen at the bottom and their physical settings were as illustrated before in Fig. (2a-c). The pressure in the wells is set to be $95.0 \mathrm{kPa}$ (or gauge pressure $5.0 \mathrm{kPa})$. Fig. (5a-c) show the gas collection rate, overall surface emission rate and gas collection efficiency from all three scenarios.

As illustrated in Fig. (5a, c), the gas collection rate and efficiency ascend with an increasing number of gas extraction wells. When there is only one well in the landfill, the gas collection rate ranges from $100 \mathrm{~m}^{3} \mathrm{hr}^{-1}$ at the beginning to $90 \mathrm{~m}^{3} \mathrm{hr}^{-1}$ at year 10 , and the collection efficiency varies from 36 to $47 \%$ during the same period; when the number of wells is doubled, the gas collection rate climbs to around $172 \mathrm{~m}^{3} \mathrm{hr}^{-1}$ at year 0 and $154 \mathrm{~m}^{3} \mathrm{hr}^{-1}$ at year 10 , and consequently, the collection efficiency jumps up to $61 \sim 81 \%$. If the number of wells present in the landfill further increases to four, the gas collection rate and efficiency increase to $280 \sim 250 \mathrm{~m}^{3} \mathrm{hr}^{-1}$ and $99 \sim 131 \%$ from year 0 to year 10 respectively. The decreasing trend of gas collection rate and the increasing trend of gas collection efficiency during the ten-year period are due to a decreasing rate of gas generation.

Inversely, the overall surface emission rate decreases with an increasing number of gas collection wells as shown in Fig. (5b). The surface emission rate ranges from 176 to 97 $\mathrm{m}^{3} \mathrm{hr}^{-1}$ in the first ten years when only one well is installed, as the number of wells goes up to two, the surface emission rate decreases to $104 \sim 32 \mathrm{~m}^{3} \mathrm{hr}^{-1}$, and when the landfill is equipped with four wells, the surface emission rate can be further lowered to $3 \sim-59 \mathrm{~m}^{3} \mathrm{hr}^{-1}$. Negative numbers indicate a gas influx or an air intrusion. Fig. (5b) shows that the overall air intrusion starts around 4 or 5 months into the operation. This explains why a gas collection efficiency of over $100 \%$ is obtained as shown in Fig. (5c).

Fig. (6) compares the gas collection rate and surface emission rate for varying number of wells at a single time point. These are active wells with a gauge pressure $-2.5 \mathrm{kPa}$ applied at year 1. As demonstrated in the plot, with each additional well added, the marginal effect decreases. For example, when there is only one well installed, the gas collection rate at year 1 is $66.6 \mathrm{~m}^{3} \mathrm{hr}^{-1}$, and the surface emission rate is $107.6 \mathrm{~m}^{3} \mathrm{hr}^{-1}$. However, when a second well is added, the overall gas collection rate is $114.5 \mathrm{~m}^{3} \mathrm{hr}^{-1}$, and 

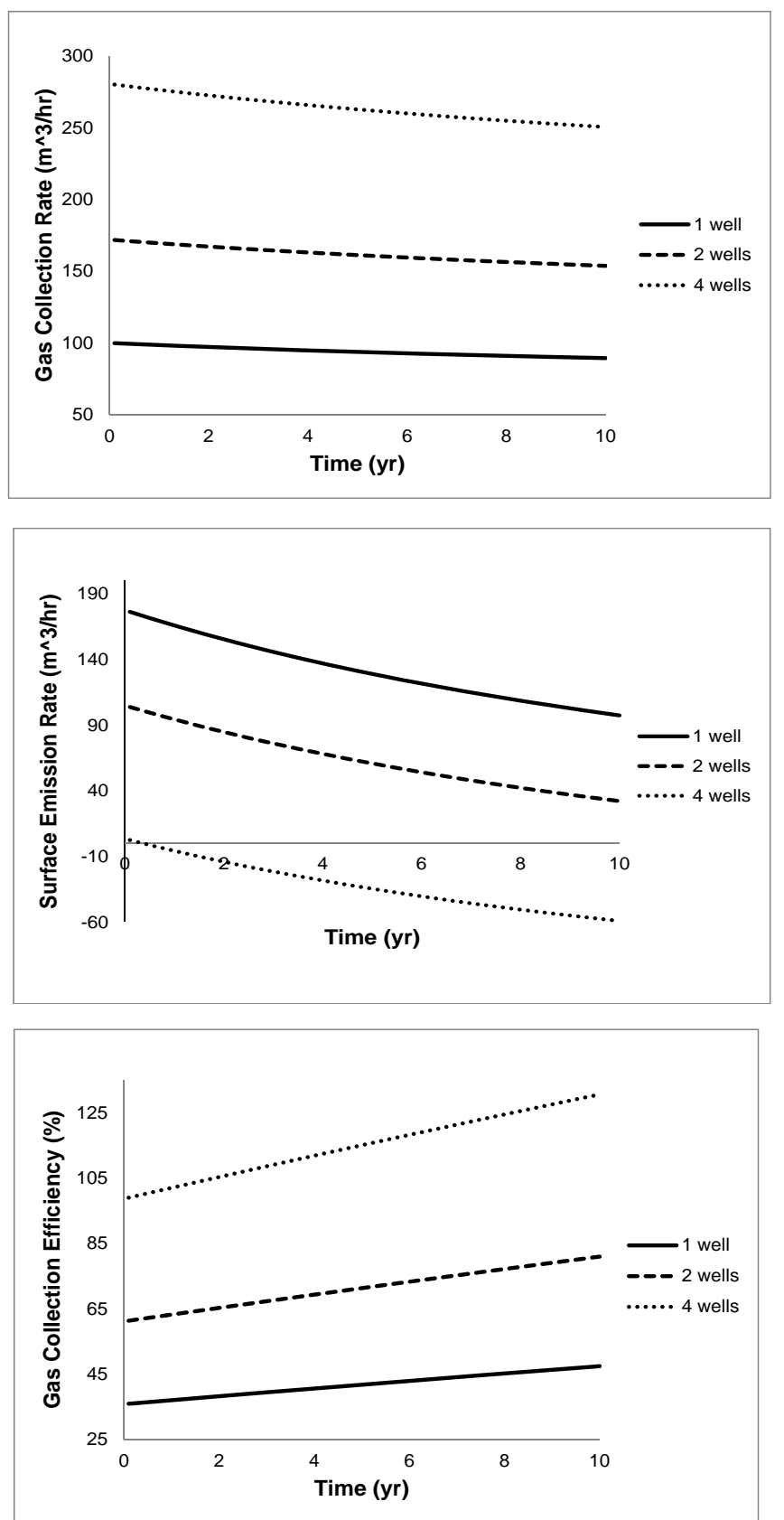

Fig. (5). (a) Overall gas collection rate of the active gas collection systems with indicated number of vertical wells at a gauge pressure of $-5 \mathrm{kPa}$; (b) Overall surface emission rate; (c) Gas collection efficiency.

the surface emission rate is $149.3 \mathrm{~m}^{3} \mathrm{hr}^{-1}$; in other words, in a two-well system, the average gas collection rate for each well decreases to 57.3 from $66.6 \mathrm{~m}^{3} \mathrm{hr}^{-1}$. If the number of wells further increases to six, then the gas collection rate for each individual well becomes only $38.0 \mathrm{~m}^{3} \mathrm{hr}^{-1}$, which is only $57 \%$ of the gas collection level of the one-well system.

Facilitating a landfill with a large quantity of wells not only helps to enhance the efficiency of a gas collection system but also increases the possibilities of minimizing surface emission while keeping air intrusion at a minimal level. Fig. (7a-c) illustrate the contours of gas flux across the entire landfill surface while Fig. (9) shows the landfill gas

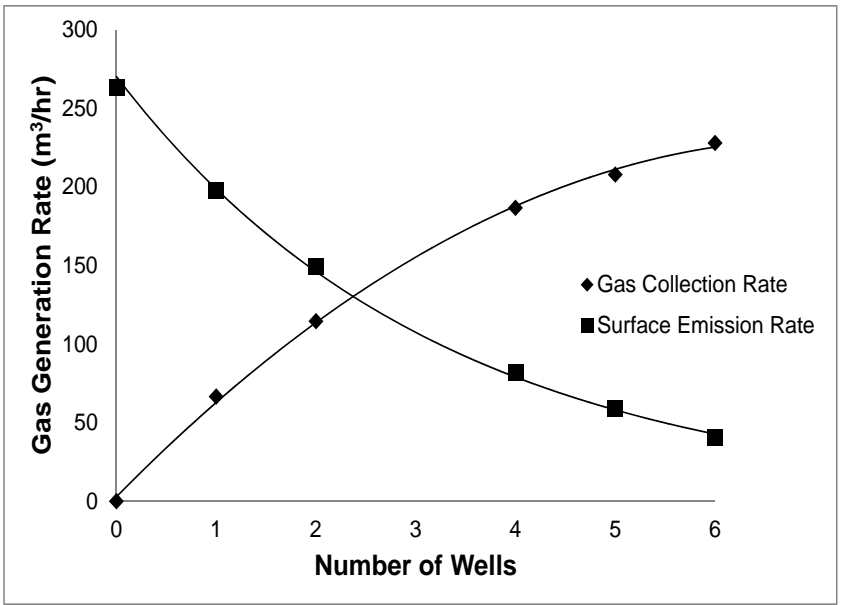

Fig. (6). Gas collection rate and surface emission rate of an active system with an indicated number of wells with a gauge pressure of $2.5 \mathrm{kPa}$ at year 1 .

flux profile at the surface along the line indicated in Fig. (8) for landfills equipped with one, two and four gas extraction wells. Figs. $(7,9)$ indicate that the gas flux through the top surface is usually lower near the wells or at the centre of the final cover since these areas are mostly affected by the gas collection system. In contrast, the gas flux is higher along the edges of the landfill since those regions are usually farther away from the wells and therefore less affected. Fig. (9) also demonstrates that the gas flux is more equal throughout the top surface when the landfill is facilitated with four wells, and as the number of wells decreases, the gas flux throughout the top surface becomes more disparate. In the case with four wells, the highest and the lowest gas flux at the surface are $2.32 \mathrm{e}-6 \mathrm{~m} \mathrm{~s}^{-1}$ and $2.20 \mathrm{e}-6 \mathrm{~m} \mathrm{~s}^{-1}$ with a difference of $1.2 \mathrm{e}-7 \mathrm{~m} \mathrm{~s}^{-1}$. If only two wells are installed, then the highest and the lowest gas flux are $4.39 \mathrm{e}-6 \mathrm{~m} \mathrm{~s}^{-1}$ and $3.82 \mathrm{e}-6 \mathrm{~m} \mathrm{~s}^{-1}$ with a larger difference of $5.7 \mathrm{e}-7 \mathrm{~m} \mathrm{~s}^{-1}$. When the number of wells becomes one, the highest and the lowest gas flux increase to $5.69 \mathrm{e}-6 \mathrm{~m} \mathrm{~s}^{-1}$ and $5.05 \mathrm{e}-6 \mathrm{~m} \mathrm{~s}^{-1}$, and the difference is further heightened to $6.4 \mathrm{e}-7 \mathrm{~m} \mathrm{~s}^{-1}$. These results suggest if the gas collection system contains only one well, it is more difficult to find a perfect vacuum pressure to apply in order to minimize both surface emission occurring farther away from the well and air intrusion taking place closer to the well. On the other hand, if four wells are installed, then finding a vacuum pressure which will keep the surface emission across the whole top surface at a minimal level while avoid any air intrusion near the centre or the wells becomes more realistic.

Figs. (10, 11a-c) present the overall surface emission rate in a ten-year time span and the gas flux profile around the time of first air intrusion occurrence under specified conditions. As Fig. (10) shows, if the vacuum pressure is fixed at $-4.0 \mathrm{kPa}$, the overall surface emission rate will first turn negative, indicating an overall air intrusion, at year 5 when four wells are in effect. However, the model indicates that the surface starts to have air intrusion near the well regions 4.4 years into the operation, which is only 0.6 year prior to the occurrence of overall air intrusion. If the landfill is facilitated with two wells and the vacuum pressure is fixed at $-7.0 \mathrm{kPa}$, then the overall air intrusion is first introduced at 


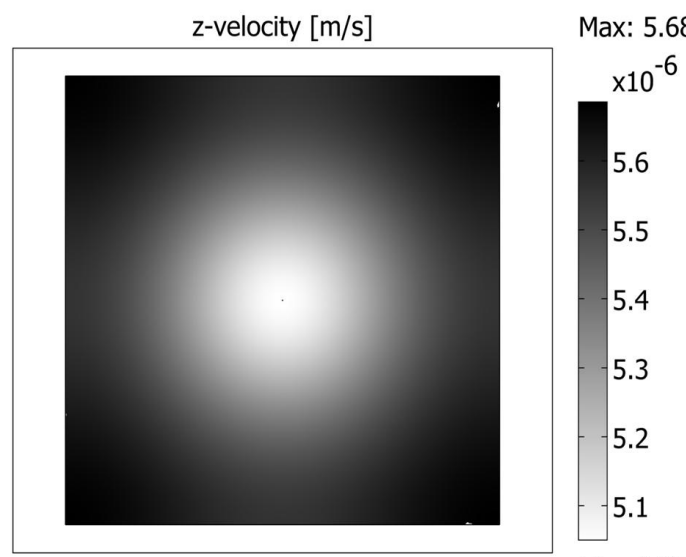

Min: $5.05 \mathrm{e}-6$

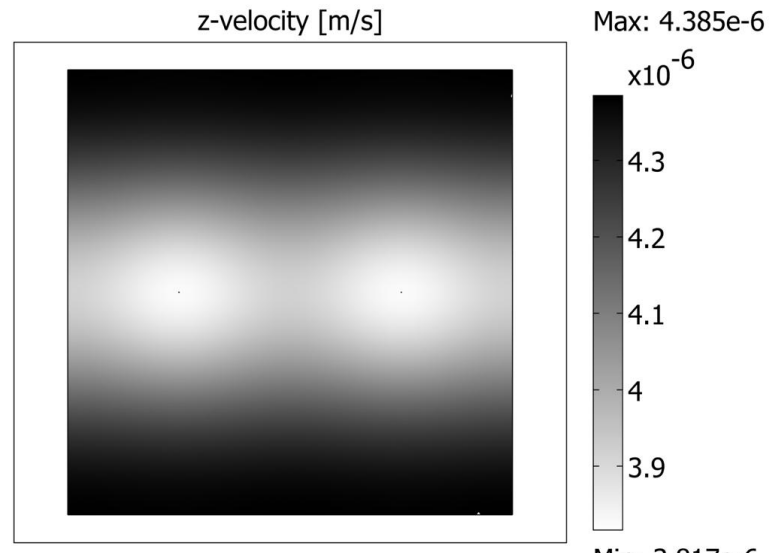

Min: $3.817 \mathrm{e}-6$

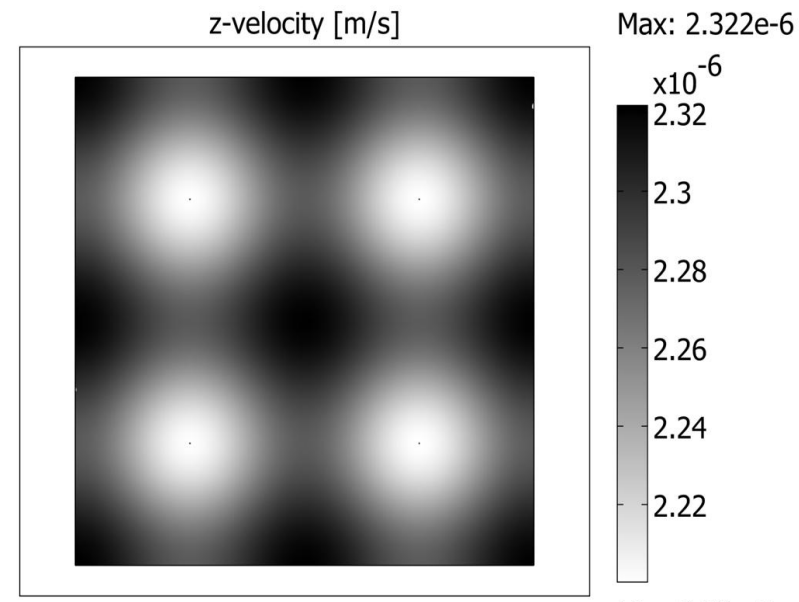

Min: $2.20 \mathrm{e}-6$

Fig. (7). Contour map of the gas flux at the top surface of the landfill equipped with a gas collection system and a gauge pressure of $2.5 \mathrm{kPa}$ at year 1 consisting of: (a) one vertical well; (b) two vertical wells; (c) four vertical wells.

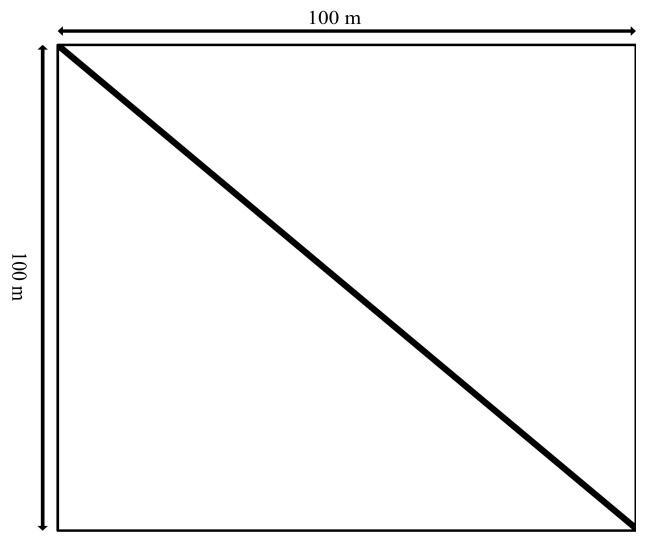

Fig. (8). The transect along where the gas flux was shown in Fig. (9).

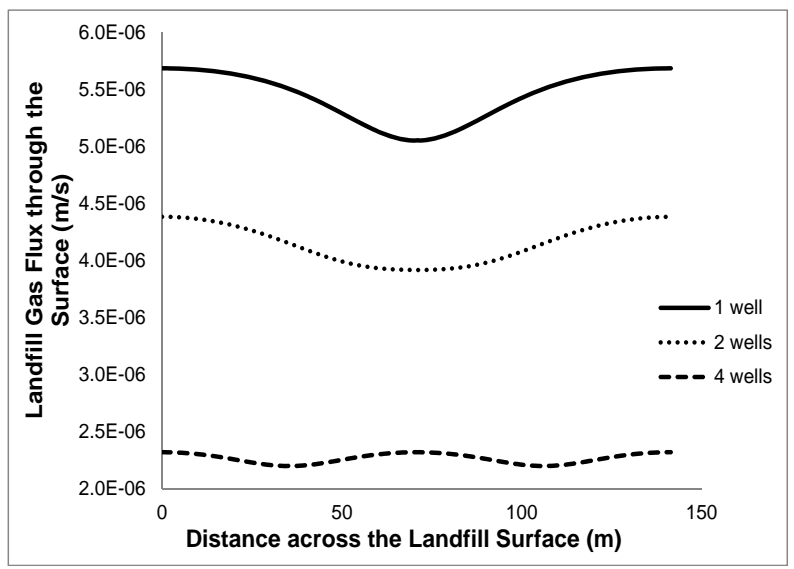

Fig. (9). Gas flux at the surface along the transect shown in Fig. (8) for a landfill with a gauge pressure of $-2.5 \mathrm{kPa}$.

year 7.5; however, air intrusion is first observed near the well regions at year 4.3, more than three years before the occurrence of overall air intrusion. In the case of only one well with the vacuum pressure fixed at $-13.0 \mathrm{kPa}$, the difference in time between the first occurrence of air intrusion near the well region (year 2.5) and overall air intrusion (year 9) is 6.5 years. A smaller time difference indicates a more equal and balanced distribution of gas flux throughout the surface.

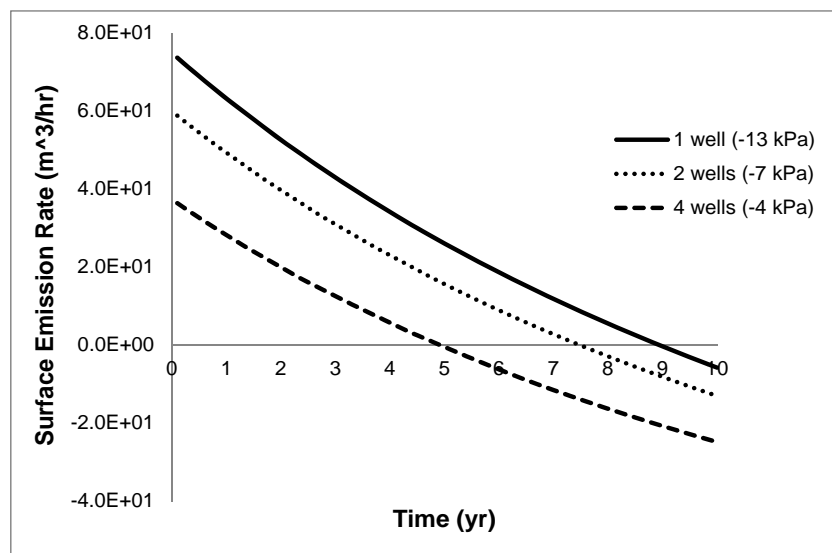

Fig. (10). Overall surface emission rate for landfills. A positive number means upward gas flux (surface emission), a negative number indicates downward gas flux (air intrusion). 

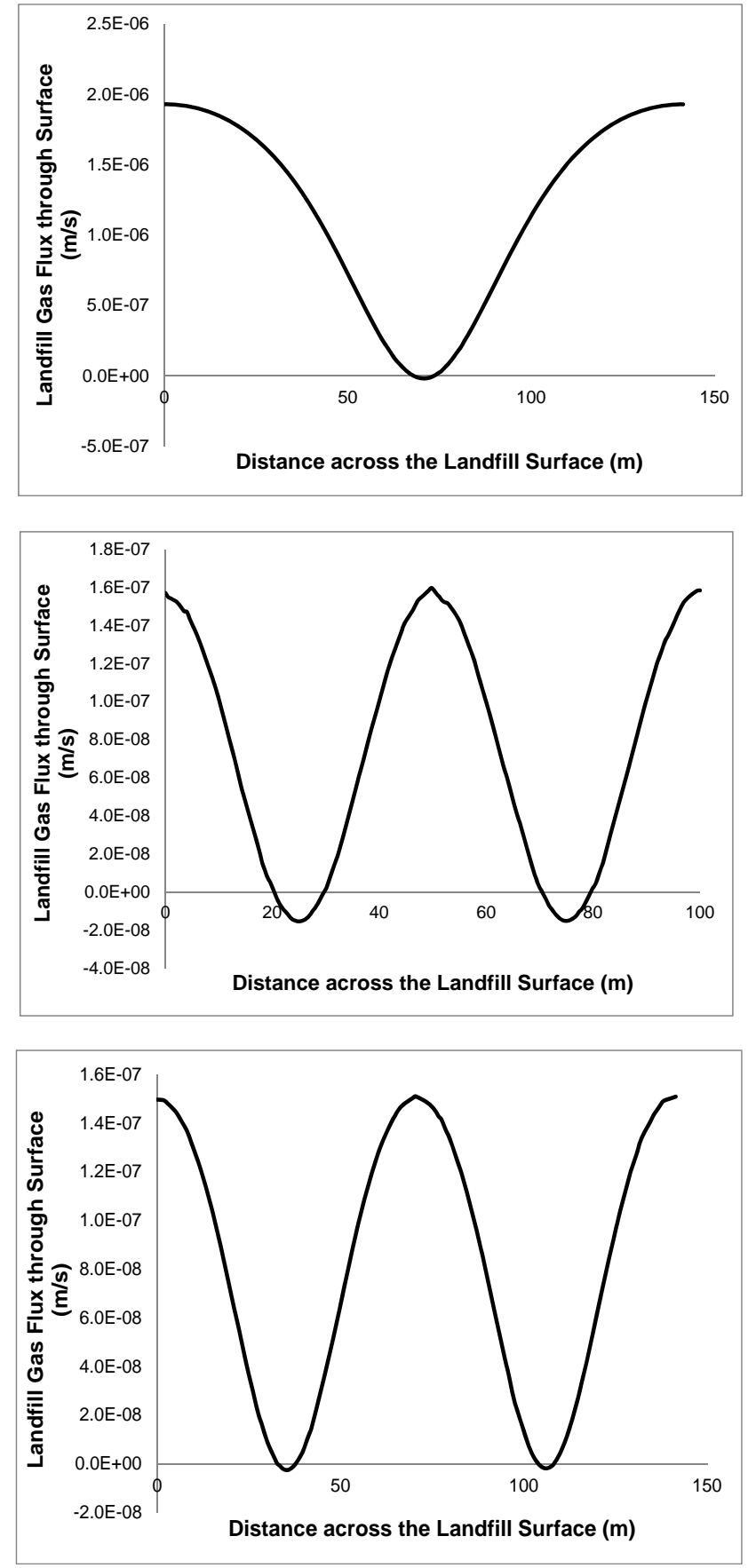

Fig. (11). (a) Gas flux at the surface of a landfill facilitated with a well with a gauge pressure of $-13.0 \mathrm{kPa}$; (b) two wells with a gauge pressure of $-7.0 \mathrm{kPa}$; (c) four wells with a gauge pressure of -4.0 $\mathrm{kPa}$.

\section{Effects of Varying the Orientation of the Gas Extraction Wells}

Investigations were conducted to study how the efficiency of a gas collection system may be impacted when the wells are placed in a different orientation. Simulations with two different settings were proposed and conducted: one contains a vertical well, and the other one contains a horizontal well. The well screen for each well is $20.0 \mathrm{~m}$ long and their centres are located $20.0 \mathrm{~m}$ above the bottom of the landfill and their settings are delineated in Figs. (1a, 2a, 12).
The pressure at the top surface and the initial pressure within the landfill were both assumed to be $100.0 \mathrm{kPa}$.

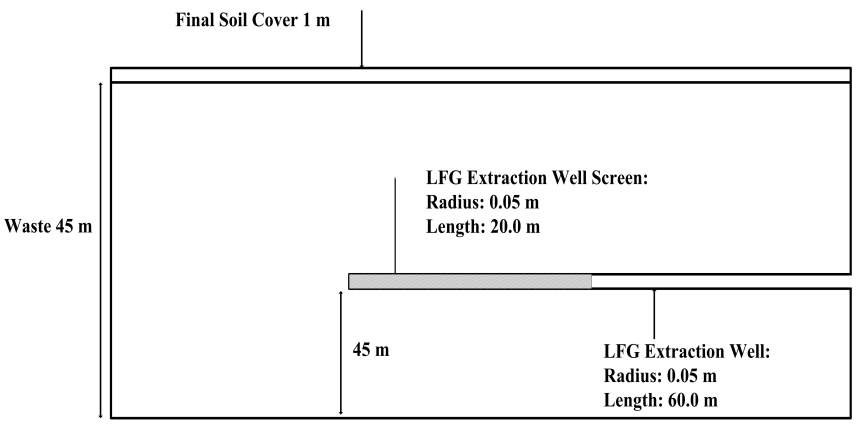

Fig. (12). A schematic illustration of the landfill facilitated with a horizontal well.

Fig. (13a-c) show the gas collection rate, overall surface emission rate and gas collection efficiency when the gauge
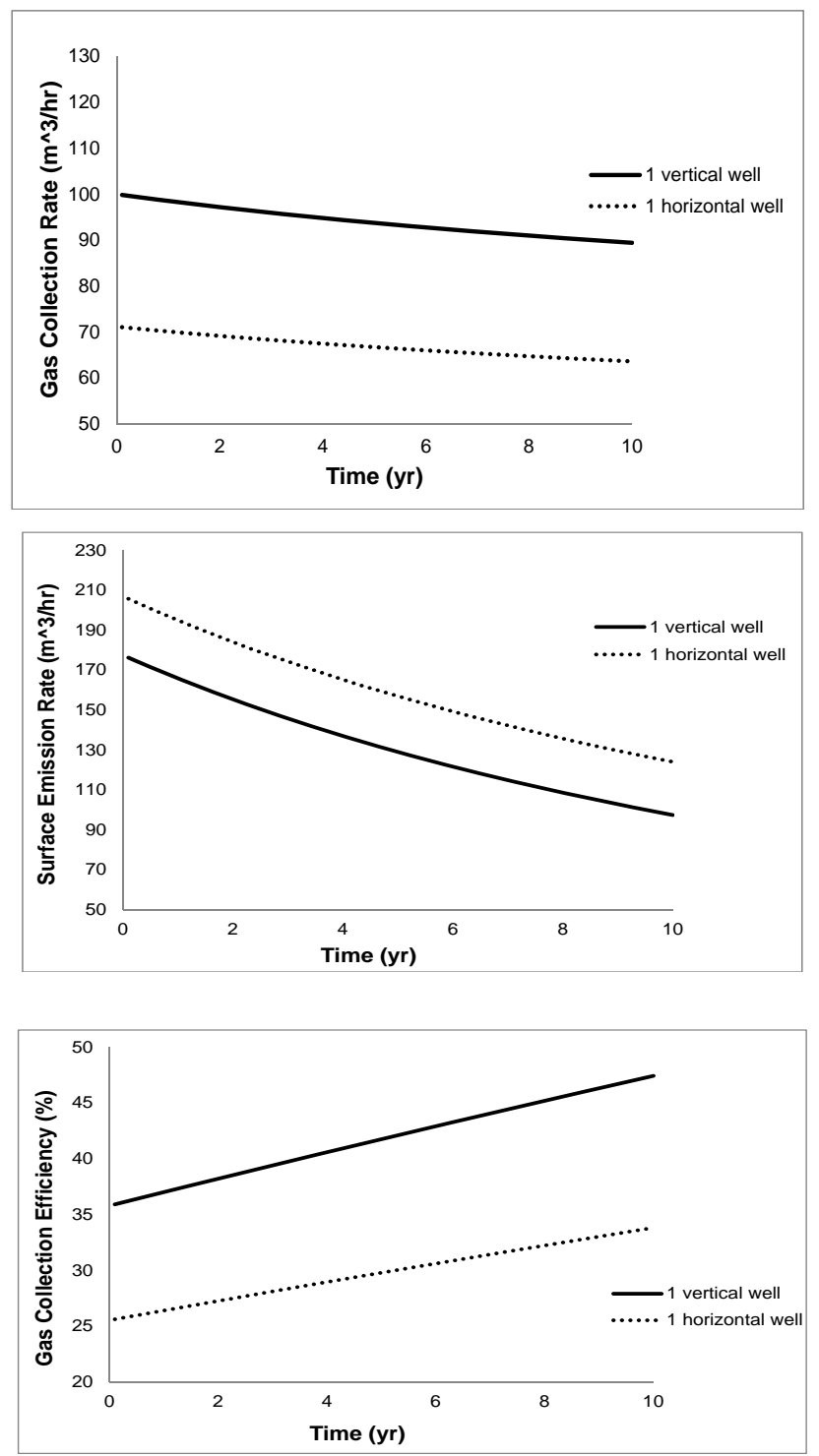

Fig. (13). (a) Gas collection rate of a system with a well in the indicated direction and a gauge pressure of $-5.0 \mathrm{kPa}$; (b) Overall surface emission rate; (c) Gas collection efficiency. 
pressure in the wells is $-5.0 \mathrm{kPa}$. The figures suggest that the gas collection system works more efficiently when it has a vertical well instead of a horizontal well for the same screen length. The gas collection efficiency is about $40.5 \%$ higher while the surface emission rate is $14.5 \sim 21.5 \%$ lower when the well is placed vertically than horizontally during the fiveyear simulated period. When the gauge pressure applied in the well is further strengthened to $-7.5 \mathrm{kPa}$ and $-10.0 \mathrm{kPa}$, similar results are observed and presented in Fig. (14a, b). The figures show that regardless of the vacuum pressure applied, the gas collection efficiency for a vertical well is consistently around $43.3 \%$ higher than a horizontal well when their centres of the screen section is located $20.0 \mathrm{~m}$ above the bottom of the landfill.
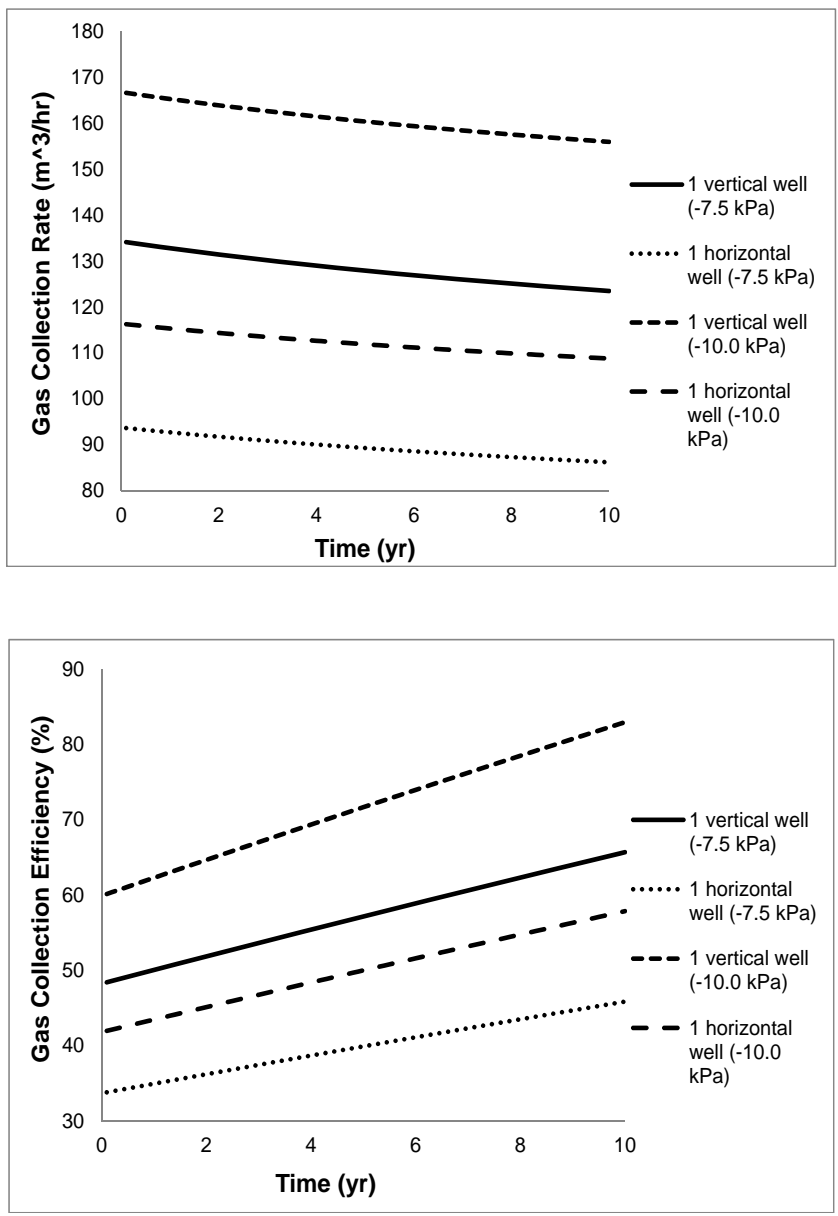

Fig. (14). (a) Gas collection rate of wells with indicated direction and gauge pressure; (b) Gas collection efficiency.

In order to find an explanation for the difference in gas collection efficiency between a vertical well and a horizontal well, the elevation of wells and the permeability in the landfill were varied, and the results are shown in Figs. (15, 16). As depicted in Fig. (15), when a horizontal well is placed $30.0 \mathrm{~m}$ above the bottom of the landfill, which is closer to the younger waste buried in the landfill, its gas collection efficiency is still around 15 to $20 \%$ lower than that of a vertical well whose screen section situated is from 10.0 to $30.0 \mathrm{~m}$ above the bottom, and it is fairly close (within 2 to $3 \%$ ) to that of a horizontal well placed at $10.0 \mathrm{~m}$ or $20.0 \mathrm{~m}$

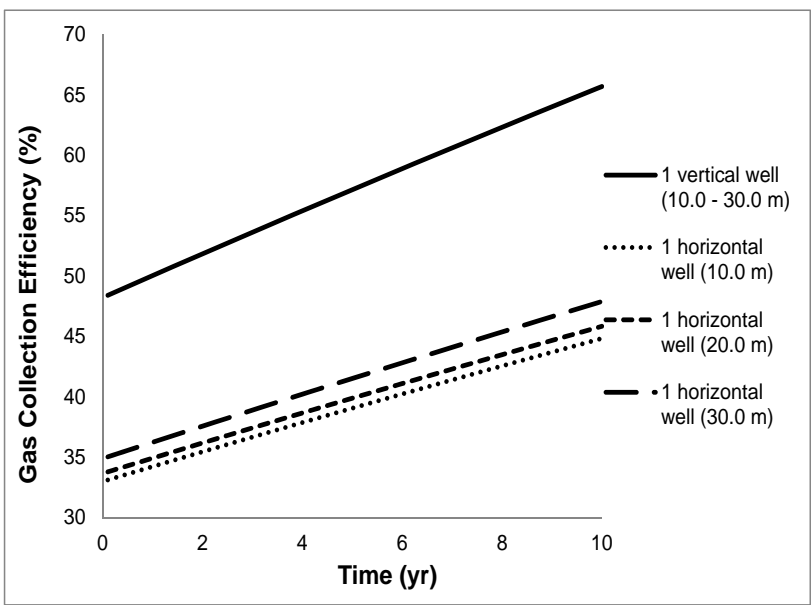

Fig. (15). Gas collection efficiency of wells with indicated direction and position.

above the bottom. These results demonstrate that the elevation of a horizontal well makes a relatively insignificant difference in its gas collection efficiency, and therefore the difference in the gas collection efficiency between a vertical well and a horizontal well is unlikely a result of where a horizontal well is placed. When the permeability of the landfill in the vertical direction is changed to $3.0 \mathrm{e} 12 \mathrm{~m}^{2}$, which is identical to the permeability in the horizontal direction, a marginal difference is observed in the gas collection efficiency amongst a vertical well with its screen section placed from 10.0 to $30.0 \mathrm{~m}$ above the landfill and the horizontal wells located at $10.0,20.0$ and $30.0 \mathrm{~m}$ above the bottom as presented in Fig. (16). These results suggest that

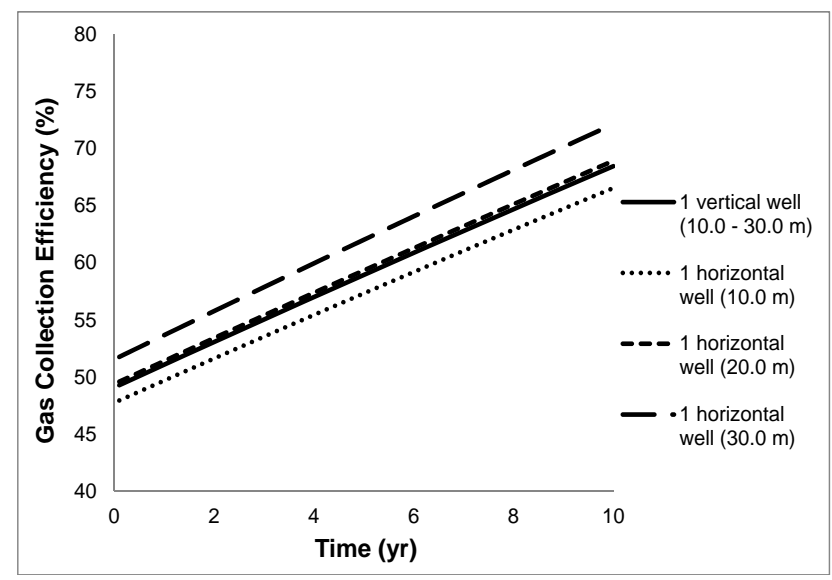

Fig. (16). Gas collection efficiency of wells with indicated direction and position in a landfill with the same permeability $\left(3.0 \mathrm{e} 12 \mathrm{~m}^{2}\right)$ in both horizontal and vertical directions.

the difference between the gas collection efficiency of a vertical well and a horizontal well is mainly due to the difference in permeability in the vertical and horizontal direction. Gas generally flows horizontally into a vertical well, but if the well is placed horizontally, the gas flow path contains a vertical component, which slows down the flow rate due to a lower permeability in the vertical direction. Therefore, with the same length of well screen, a vertical well works more efficiently than a horizontal well. This finding aligns with the information presented in Landfill Gas 
Management Facilities Design Guidelines [15] published by British Columbia Ministry of Environment, which states that in a typical situation a vertical gas extraction well collects more gas than a horizontal trench.

\section{CONCLUSIONS}

Comparisons among active and passive systems with different number of wells and different direction of wells are conducted with intent to gain a better understanding on how to maximize gas extraction while minimize the surface emission and air intrusion by manipulating the configuration of gas wells.

The results show that for a passive gas collection system, the effectiveness can be improved by $150 \%$ for the simulated period of ten years when the number of well is increased from one to four, and the surface emission can be lowered by more than $40 \%$. The efficiency of an active gas collection system with gauge pressure of $-5 \mathrm{kPa}$ can be enhanced by $180 \%$ during the ten-year simulated period if the number of wells is increased from one to four.

A larger number of wells not only elevates the efficiency of a gas collection system but also helps reduce the surface emission while prevents undesired air intrusion. As the results suggest, the gas flux at the surface is much more equal across the entire final cover when the landfill is facilitated with four wells but relatively unequal when there is only one well installed.

When a single well with a screen length of $20.0 \mathrm{~m}$ is placed $10.0 \mathrm{~m}$ above the bottom of the landfill vertically, the gas collection efficiency for the first ten years can be boosted up by $40 \sim 43 \%$ as compared to a well horizontally placed at $20.0 \mathrm{~m}$ above the bottom, and the surface emission rate can also be reduced by $15 \sim 20 \%$ provided if the gauge pressure in the well is $-5.0 \mathrm{kPa}$. This is because a landfill is usually more permeable in the horizontal direction than in the vertical direction due to the compaction in the vertical direction.

\section{CONFLICT OF INTEREST}

The authors confirm that this article content has no conflict of interest.

\section{ACKNOWLEDGEMENT}

Funding: Natural Sciences and Engineering Research Council of Canada.

\section{REFERENCES}

[1] M. A. Barlaz, R. K. Ham and D. M. Schaefer, "Mass-balance analysis of anaerobically decomposed refuse," J. Environ. Eng., vol. 115, pp. 1088-1102, 1989.

[2] C. Chiemchaisri, W. Chiemchaisri, S. Kumar and J. P. A. Hettiaratchi, "Solid waste characteristics and their relationship to gas production in tropical landfill," Environ. Monit. Assess., vol. 135, pp. 41-48, 2007.

[3] A. Garg and G. Achari, "A comprehensive numberical model simulating gas, heat and moisture transport in sanitary landfills and methane oxidation in fianl covers," Environ. Model. Assess., vol. 15, pp. 397-410, 2010.

[4] U. Hegde, T.-C. Chang and S.-S. Yang, "Methane and carbon dioxide emissions from Shan-Chu-Ku landfill site in northern Taiwan," Chemosphere, vol. 52, pp. 1275-1285, 2003.

[5] K. Ozcan, N. Balkaya, E. Bilgili, G. Demir, N. Ucan and C. Bayat, "Modeling of methane distribution in a landfill using genetic algorithms," Environ. Eng. Sci., vol. 26, pp. 441-449, 2009.

[6] S. Molins, K. U. Maayer, C. Scheutz and P. Kjeldsen, "Tansport and reaction process affecting the attenuation of landfill gas in cover soils," J. Environ. Qual., vol. 37, pp. 459-468, 2008.

[7] L. Yu, F. Batlle, J. Carrera and A. Lloret, "Gas flow to a vertical gas extraction well in deformable MSW landfills," J. Hazard. Mater., vol. 168, pp. 1404-1416, 2009.

[8] J. P. A. Hettiaratchi, O. D. Hurtado, C. Hunte, J. Hundal, C. Colbryn and C. Smith, "The Calgary Biocell: a case study in sustainable solid waste management," In Proceedings of the International Conference on Sustainable Solid Waste Management, Chennai, India, 2007, pp. 421-428.

[9] J. Im, S. Moon, K. Nam, Y. J. Kim and J. Y. Kim, "Estimation of mass transport parameters of gases for quantifying $\mathrm{CH}_{4}$ oxidation in landfill soil covers," Waste Manage., vol. 29, pp. 869-875, 2009.

[10] R. H. Kettunen, J. K. M. Einola and J. A. Rintala, "Landfill methane oxidation in engineered soil columns at low temperature," Water Air Soil Poll., vol. 177, pp. 313-334, 2006.

[11] United States Environmental Protection Agency, "Municipal solid waste generation, recycling and disposal in the United States: facts and figures for 2007," ed. United States Environmental Protection Agency: Washington, DC, 2008.

[12] T. G. Townsend, W. R. Wise and P. Jain, "One-dimensional gas flow model for horizontal gas collection systems at municipal solid waste landfills," J. Environ. Eng., vol. 131, pp. 1716-1723, 2005.

[13] W. McCain, The properties of petroleum fluids, 2 ed. PennWell Publishing Company: Tulsa, Oklahoma, 1990.

[14] Y.-C. Chen, K.-S. Chen and C.-H. Wu, "Numerical simulation of gas flow around a passive vent in a sanitary landfill," J. Hazard. Mater., vol. B100, pp. 39-52, 2003.

[15] Conestoga-Rovers \& Associates, "Landfill gas management facilities design guidelines," British Columbia Ministry of Environment, Ed., ed. British Columbia Ministry of Environment: Richmond, BCS, 2010. 